\title{
The quality of screening colonoscopies in an office-based endoscopy clinic
}

\author{
Douglas Bair MD FRCPC ${ }^{1,2}$, Joe Pham MD FRCPC ${ }^{1,2}$, M Bianca Seaton MSc ${ }^{3}$, Naveen Arya MD FRCPC ${ }^{1,2}$, \\ Michelle Pryce ${ }^{1}$, Trevor L Seaton MB FRCPC ${ }^{1,4}$
}

D Bair, J Pham, MB Seaton, N Arya, M Pryce, TL Seaton. The quality of screening colonoscopies in an office-based endoscopy clinic. Can J Gastroenterol 2009;23(1):41-47

BACKGROUND: Wait times for hospital screening colonoscopy have increased dramatically in recent years, resulting in an increase in patient referrals to office-based endoscopy clinics. There is no formal regulation of office endoscopy, and it has been suggested that the quality of service in some office locations may be inferior to hospital procedures.

OBJECTIVE: To compare the quality of office-based screening colonoscopies at a clinic in Oakville, Ontario, with published benchmarks for cecal intubation, withdrawal times, polyp detection, adenoma detection, cancer detection and patient complications.

METHODS: Demographic information on consecutive patients and colonoscopy reports by all nine gastroenterologists at the Oakville Endoscopy Centre between August 2006 and December 2007 were prospectively obtained.

RESULTS: A total of 3741 colonoscopies were analyzed. The mean age of patients was 57.1 years and $51.9 \%$ were women. The cecal intubation rate was $98.98 \%$ with an average withdrawal time of $9.75 \mathrm{~min}$. A total of 3857 polyps were retrieved from 1725 patients (46.11\%), and 1721 adenomas were detected in 953 patients $(25.47 \%)$. A total of 126 patients $(3.37 \%)$ had advanced polyps and $18(0.48 \%)$ were diagnosed with colon cancer. One patient $(0.027 \%)$ had a colonic perforation and two patients had postpolypectomy bleeding $(0.053 \%)$. These results meet or exceed published benchmarks for quality colonoscopy.

CONCLUSIONS: The Oakville Endoscopy Centre data demonstrate that office-based colonoscopies, performed by well-trained physicians using adequate sedation and hospital-grade equipment, result in outcomes at least equal to or better than those of published academic/community hospital practices and are therefore a viable option for the future of screening colonoscopy in Canada.

Key Words: Colon cancer; Office-based; Screening colonoscopy

\section{La qualité des coloscopies de dépistage dans un cabinet d'endoscopie}

HISTORIQUE : Les temps d'attente pour subir une coloscopie de dépistage en milieu hospitalier se sont considérablement allongés ces dernières années, ce qui entraîne une augmentation des aiguillages vers les cabinets d'endoscopie. Il n'existe pas de réglementation officielle à l'égard de l'endoscopie en cabinet, et il a été postulé que la qualité des services de certains cabinets est inférieure à celle des interventions en milieu hospitalier.

OBJECTIFS : Comparer la qualité des coloscopies de dépistage en cabinet à une clinique d'Oakville, en Ontario, avec les normes publiées d'intubation cæcale, les temps de retrait, la détection des polypes, des adénomes et des cancers ainsi que les complications que vivent les patients.

MÉTHODOLOGIE : Les auteurs ont obtenu prospectivement l'information démographique sur des patients consécutifs et les rapports de coloscopie par les neuf gastroentérologues du centre d'endoscopie d'Oakville entre août 2006 et décembre 2007.

RÉSULTATS : Au total, les auteurs ont analysé 3741 coloscopies. Les patients avaient un âge moyen de 57,1 ans et 51,9\% étaient des femmes. Le taux d'intubation cæcale était de 98,98\%, avec un temps moyen de retrait de 9,75 minutes. Au total, on a extrait 3857 polypes chez 1725 patients (46,11\%) et décelé 1721 adénomes chez 953 patients (25,47\%). Au total, 126 patients $(3,37 \%)$ avaient des polypes avancées et $18(0,48 \%)$ ont reçu un diagnostic de cancer du côlon. Un patient $(0,027 \%)$ a subi une perforation du côlon et deux patients $(0,053 \%)$, des saignements postpolypectomies. Ces résultats respectent ou dépassent les normes publiées relativement à des coloscopies de qualité.

CONCLUSIONS : Les données du centre d'endoscopie d'Oakville démontrent que les coloscopies en cabinet, effectuées par des médecins bien formés au moyen d'une sédation adéquate et de matériel de qualité hospitalière, assurent des issues au moins équivalentes sinon meilleures que celles des pratiques des hôpitaux universitaires ou généraux publiés et constituent donc une option viable pour l'avenir des coloscopies de dépistage au Canada.

As a result of the longer wait times for hospital procedures, patients are increasingly being referred to office-based endoscopy clinics. There is no formal regulation of office-based endoscopy centres, and it has been suggested that the quality of service in some centres may be inferior to hospital procedures, with higher rates of missed colorectal cancers and incomplete procedures in the office-based settings $(4,5)$. Even in the United States, where out-of-hospital colonoscopy is a common practice, there are little data regarding outcomes of community procedures (6). The discrepancy between office-based and inhospital endoscopy may be due to the fact that historically in Ontario, office-based colonoscopies have been conducted by less than six months for screening colonoscopy (3).

\footnotetext{
${ }^{1}$ Oakville Endoscopy Centre, ${ }^{2}$ Oakville Trafalgar Memorial Hospital, Oakville; ${ }^{3}$ Dalla Lana School of Public Health, University of Toronto, Toronto;

${ }^{4}$ Faculty of Health Sciences, McMaster University, Hamilton Health Sciences, Hamilton, Ontario

Correspondence and reprints: Dr Douglas Bair, Oakville Endoscopy Centre, 690 Dorval Drive, Suite 125A, Oakville, Ontario L7K 3 W7.

Telephone 905-842-3666, fax 905-842-3330, e-mail douglasbair@gmail.com

Received for publication July 6, 2008. Accepted September 25, 2008
} 
lesser-trained nongastroenterologists, and those without hospital privileges using less than hospital standards for sedation, nursing and equipment. Furthermore, there is currently no meaningful technical fee for out-of-hospital endoscopy in Ontario. Thus, financial imperatives may also have contributed to the lower standards of office-based endoscopy procedures.

To combat the longer wait times for hospital-based colonoscopies at our local suburban hospital in Oakville, Ontario, we created the Oakville Endoscopy Centre (OEC) in 2006. The goal of the OEC is to match the standards of care and outcomes of any regional hospital or international standard, while shortening wait times.

The OEC is an office-based clinic that provides only screening and surveillance colonoscopies. All OEC physicians have hospital privileges, which allows for hospital management of rare complications. The OEC provides hospital-grade standards for equipment, sedation, sterilization, monitoring and staffing as set out by the College of Physicians and Surgeons of Ontario (CPSO) and Cancer Care Ontario (CCO). In addition, the OEC provides a relaxed atmosphere to alleviate anxiety, and may be preferred over a hospital setting by patients.

The objective of the present study was to compare the quality of the office-based screening colonoscopies at the OEC with published benchmarks for cecal intubation, withdrawal times, polyp detection, adenoma detection, advanced adenoma detection, cancer detection and patient complications such as hospital admission for postpolypectomy bleeding and perforation.

\section{METHODS}

Between August 2006 and December 2007, a prospective, singlecentre study involving 3741 consecutive office-based screening colonoscopies was performed. The following is a detailed description of the patients, procedure specifics, setting and data analysis practices for the present study.

\section{Study population}

All patients seen at the OEC during the study period were included in the present analysis. All patients seen at the OEC are referred via a general practitioner. Patients were prescreened by their referring physician and the OEC, to maximize the safety of the patient's office-based colonoscopy. Patients understood the rationale for screening colonoscopies through discussions with their referring physician, information provided on the OEC Web site, and with their endoscopist at the time of consultation. Standard criteria for screening included age-related risk (ie, older than 50 years of age), family history or a positive fecal occult blood test. Standard criteria for surveillance included history of previous colon cancer or polyps, family history or long-standing inflammatory bowel disease. Exclusion criteria for referral included age older than 75 years, active coronary artery disease, severe respiratory disease (home oxygen), renal failure (creatinine levels greater than $200 \mu \mathrm{mol} / \mathrm{L}$ ), active gastrointestinal bleeding and patients on warfarin therapy. Written consent was obtained by the endoscopist at the time of consultation, before the procedure.

\section{Facility and staffing}

The OEC is approximately $914 \mathrm{~m}^{2}$, with one $61 \mathrm{~m}^{2}$ procedure room and a total of eight recovery beds. Each procedure is scheduled to last for $30 \mathrm{~min}$ and a total of 14 procedures are performed daily at the OEC. The CPSO draft was followed for operating and constructing an endoscopy centre in the creation of the OEC. A local infectious disease consultant reviewed the centre's infection control measures. Professional engineering was required to construct the unit's ventilation system to obtain adequate air exchange.

There is one dedicated endoscopy nurse per endoscopy room and one dedicated recovery room nurse per room at the clinic (both are generally registered nurses). A dedicated endoscope reprocessor is on staff, trained and credentialed by the endoscope manufacturer and endoscope reprocessing manufacturer. The clinic's medical staff members are all subspecialty gastroenterologists and the majority have at least one year of additional endoscopic training beyond the mandatory core gastroenterology training. The clinic is staffed by five community and four academic gastroenterologists with a practice duration range of one to 32 years.

\section{Bowel preparation}

The bowel preparation for colonoscopy consisted of two tablets of bisacodyl taken the day before colonoscopy and a twodose preparation of Pico-Salax ${ }^{\circledR}$ (Ferring Inc, Canada) (each sachet contains sodium picosulfate $10 \mathrm{mg}$, and magnesium oxide $3.5 \mathrm{~g}$ and citric acid $12 \mathrm{~g}$ ) one taken at 17:00 the day before the procedure and the second dose at least $3 \mathrm{~h}$ preprocedure on the day of the examination.

Patients were advised not to take acetylsalicylic acid and all nonsteroidal anti-inflammatory drugs for five days before their procedure.

\section{Sedation and monitoring}

Conscious sedation is the standard practice at the OEC and was used for the patients in the present study. Patients are generally given midazolam and fentanyl at doses equivalent to those used for in-hospital procedures, at the endoscopists' discretion. Pulse oximetry, blood pressure and telemetry monitoring were used during the procedures. Supplemental oxygen was provided as needed, and all patients were monitored for oxygen saturation and blood pressure in the eight-bed recovery area. Resuscitation equipment at the OEC includes a hospital-grade 'crash cart' with defibrillation, cardiac medications, reversal agents and endotracheal intubation set-up. All physicians are qualified internists with endotracheal intubation skills. The clinic contains an emergency power source and an evacuation protocol.

\section{Equipment}

The clinic uses the Steris System 1 (Steris, USA) high-level disinfection processor systems and Steris 20 Sterilant Concentrate and Klenzyme (Steris, Canada) solutions. The colonoscopes used in the present study were a combination of adult and pediatric Pentax 30 (Pentax, USA) series video colonoscopes, and are generalizable to clinical practice. Standard techniques were used by avoiding wide-angle colonoscopes, narrow band imaging, chromoendoscopy and withdrawal in retroflexion. Photo documentation of the terminal ileum, appendiceal orifice, ileocecal valve and retroflexion in the rectum are captured with a Medicapture Unit (Medicapture, USA) (Model USB 100). Disposable accessory equipment includes Boston Scientific (Boston Scientific, USA) mini-snares, biopsy forceps, endoclips and hot biopsy forceps. The ERBE ICC 200 (ERBE, USA) cautery system was used. Monitors include the Welch Allyn Atlas Monitor (Welch Allyn, USA) (electrocardiogram monitoring) and VSM 300 monitors. 
TABLE 1

Outcome comparison with Cancer Care Ontario (CCO) and reference standards

\begin{tabular}{|c|c|c|c|}
\hline & CCO standards (8) & Canadian and American tertiary hospitals & Oakville Endoscopy Centre \\
\hline $\begin{array}{l}\text { Cecal intubation rate, \% } \\
\text { (reference) }\end{array}$ & 95 & 92 (11); 90 to 95 (16), 95 (14) & 98.98 \\
\hline Withdrawal time, $\min$ (reference) & No definitive recommendation & $>6(19) ;>7(9)$ & 7.57 \\
\hline Cancer detection rate, $\%$ & No definitive recommendation & No definitive recommendation & 0.48 \\
\hline
\end{tabular}

\section{Completion, complications and polyp assessment}

Cecal intubation was determined by the individual endoscopist based on visualization of the appendiceal orifice, ileocecal valve and in most cases, intubation of the terminal ileum. Photo documentation of these landmarks began in June 2007. Before photo documentation, the policy of the clinic was to have a second person (usually the endoscopy nurse) verify the identification of these landmarks, which was also documented. The clinic maintains an electronic record of all photographs in the OEC database. Three of the authors reviewed a 20\% random sample of the photographs collected during the study period to confirm the results recorded in the database.

The reasons for incomplete cecal intubations were classified as being due to poor patient preparation, looping and/or redundancy, obstructing mass, patient discomfort, patient hemodynamic or respiratory instability, or other. Notes were made of diverticulosis or previous abdominal or pelvic surgery as part of the routine data collected before and during the procedure.

Polyp removal was taken from the endoscopy reports and confirmed from the pathology reports. Similarly, advanced adenoma and carcinoma were based on the pathology reports. Polyps larger than $1 \mathrm{~cm}$ in diameter, or reported as having villous architecture or high-grade dysplasia, were considered advanced adenomas.

Complications were tracked via direct patient communication with the OEC, reports from local hospitals and from referring physicians. All patients were given written instructions to contact the OEC first if they had any questions or concerns postprocedure, and are given a contact telephone number for the OEC that is accessible $24 \mathrm{~h}$ per day on their postprocedure information instructions. In addition, the OEC physicians provide the inpatient and $24 \mathrm{~h}$ on-call for the gastroenterology service at all three regional hospitals in the vicinity of the OEC. Therefore, it would be unusual for a patient with a postprocedure complication to not encounter an OEC physician for inpatient care should they visit a local hospital. Furthermore, the general practitioners who refer all patients to the clinic are given written instructions to contact the $\mathrm{OEC}$ in the event of a postprocedure complication. Hence, the complication rate for the present study is thought to be accurate.

\section{Follow-up protocol}

Patients are initially given a postcolonoscopy procedure sheet with initial findings of the procedure. All pathology is reviewed by the OEC physician who performed the procedure. A follow-up sheet with the recommended follow-up interval is then faxed to the referring general practitioner. The intervals are then entered into the OEC administrative software. Monthly recall sheets are produced by the software and the referring physicians are then contacted to arrange the patient's follow-up procedures. The follow-up intervals are based on the guidelines suggested by the CAG (7). Any deviation from the guidelines requires a documented explanation by the endoscopist (eg, inadequate bowel preparation).

\section{Data analysis}

A customized Web-based database was created by the OEC and Affirmative Software Technologies (Affirmative Software Technologies, Canada) to maintain patient records. Detailed patient demographics and procedure-specific information including endoscopy time, preparation quality, findings, complications and pathology are collected and maintained in this database. Cecal intubation rates, polyp rates and procedure times were collected for the entire group and for all nine individual physicians. Standard deviations and 95\% CIs were calculated.

Given the low number of patient complications during the study period (three cases), no statistical analysis of the complication rate was attempted.

The 2007 CCO colonoscopy guidelines (8) were used as the main comparative benchmarks for the OEC data. The OEC data were also compared with other published guidelines and case series with similar populations (9-16) (Table 1).

\section{Subjects}

\section{RESULTS}

The baseline characteristics of the study subjects are presented in Table 2. During the study period, 3741 consecutive patients were assessed by nine OEC endoscopists. Of the screening subjects, 1940 (51.86\%) were women and 1801 (48.14\%) were men, 2596 (69.39\%) were at average risk for colon cancer, 985 (26.33\%) had a family history of colon cancer, 107 (2.86\%) had previous colonic polyps, $17(0.45 \%)$ had previous colon cancer and $36(0.96 \%)$ had positive fecal occult blood tests. The overall mean age of the patients was 57.1 years.

\section{Sedation and cecal intubation}

The mean sedation dose used during colonoscopies performed at the OEC was $4.27 \mathrm{mg}$ of midazolam and $99.2 \mu \mathrm{g}$ of fentanyl. This dosage resembles that routinely used in hospital practice $(17,18)$ and ensures patient comfort and safety. A reversal agent was very rarely used during colonoscopies performed at the OEC (five of 3471 procedures).

The mean cecal intubation rate was $98.98 \%$, with a range of $93.55 \%$ to $100 \%$. Reasons for failure of cecal intubation included poor bowel preparation (20 cases), previous abdominal 
TABLE 2

\section{Patient demographics}

\begin{tabular}{lrc}
\hline Demographic & $\mathbf{n}$ & $\%$ \\
\hline Patients/procedures, $\mathrm{n}$ & 3741 & - \\
Age, years (mean) & \multicolumn{2}{c}{57.14} \\
Men/women & $1801 / 1904$ & $48.14 / 51.86$ \\
Indication for screening colonoscopy & & \\
Average-risk & 2596 & 69.39 \\
Family history & 985 & 26.33 \\
Previous polyps & 107 & 2.86 \\
Previous cancer & 17 & 0.45 \\
Positive fecal occult blood test & 36 & 0.96 \\
\hline
\end{tabular}

or pelvic surgery (one case), diverticulosis (four cases), looping (nine cases), sharp angulation (one case), obstructing mass (one case) and adverse reaction to medications (two cases).

\section{Time to cecum and withdrawal times}

The mean time to reach the cecum was $7.47 \mathrm{~min}$ (range $5.07 \mathrm{~min}$ to $18.42 \mathrm{~min}$ ). The average withdrawal time with polyps and without polyps were $11.72 \mathrm{~min}$ (range $9.05 \mathrm{~min}$ to $16.79 \mathrm{~min}$ ) and $7.57 \mathrm{~min}$ (range $5.15 \mathrm{~min}$ to $11.50 \mathrm{~min}$ ), respectively (Table 3).

\section{Polyp, adenoma, advanced adenoma and colon cancer detection}

Among the 3741 subjects, 1725 (46.11\%) had polypoid lesions. The most common lesions detected in 1048 (28.01\%) subjects were hyperplastic polyps. Adenomas were detected in $953(25.47 \%)$ subjects and advanced adenomas were detected in $126(3.37 \%)$ subjects. Colorectal cancer was discovered in $18(0.48 \%)$ patients. Based on the TMN staging system, most patients had early-stage cancer, with five patients having stage 0 , nine patients having stage 1 , one patient having stage 2 and three patients having stage 3 colon cancer. No patients had stage 4 colon cancer (Table 4).

Patients were more likely to have colorectal cancer if the screening indication was a positive fecal occult blood test $(8.33 \%)$, compared with family history $(0.30 \%)$ and averagerisk screening $(0.46 \%)$. No patients with previous polyps or colorectal cancer were found to have colorectal cancer. Advanced adenomas were found more frequently in patients who had a positive fecal occult blood test $(11.11 \%)$ compared with the other groups: cancer surveillance $(5.88 \%)$, those with family history $(3.65 \%)$, average-risk patients $(3.16 \%)$ and polyp surveillance group (2.80\%) (Table 4$)$.

The detection of adenomas increased steadily as the age of patients increased. Patients younger than than 40 years of age had a rate of $8.77 \%$; patients who were 40 to 50 years of age had a rate of $19.01 \%$; patients aged 51 to 70 years had a rate of $26.55 \%$; and those older than 70 years had a rate of $34.23 \%$ (Table 5).

\section{Patient complications}

There were two postpolypectomy bleeds $(0.053 \%)$ that required hospitalization at the local hospital and both underwent repeat therapeutic colonoscopies by OEC physicians. Both patients had bleeding vessels at the polypectomy site and hemostasis was achieved using mechanical clipping. One subject was admitted for three days and was transfused four units of blood. The other patient was admitted for four days and received six units of blood.
There was one perforation after a snare polypectomy with electrocautery $(0.027 \%)$ that required hospital admission and surgery. There were no deaths.

\section{Comparison of OEC data with published benchmarks}

Table 1 presents a comparison of the OEC data with published benchmarks for quality colonoscopy and similar case series. The mean cecal intubation rate of $98.98 \%$ at the OEC is higher than the $95 \%$ rate recommended by CCO (8), the $95 \%$ recommended by the CPSO (14), the $90 \%$ recommended by the Joint Advisory Group on Gastrointestinal Endoscopy from the United Kingdom (15), and the $90 \%$ to $95 \%$ recommended by the US Multi-Society Task Force on Colorectal Cancer (16).

The OEC average withdrawal time when no polyps were removed of 7.57 min exceeds the published recommendations of 6 min from Simmons et al (19) and 7 min in the study by Barclay et al (9) for polyp detection.

For the 3741 subjects included in the present study, OEC physicians observed that $46.11 \%$ had polypoid lesions, $25.47 \%$ had adenomas, and $3.37 \%$ had advanced adenomas. CCO has not made definitive recommendations on these performance measures (adenoma and cancer detection rates) due to insufficient data. However, these OEC rates exceed the 15\% to $25 \%$ adenoma detection rate recommended by the US Multi-Society Task Force on Colorectal Cancer (16), and are similar to the rates reported in several comparable case series $(9,11-13)$.

The OEC rates for perforation $(0.027 \%)$ and postpolypectomy bleeding $(0.053 \%)$ match published detection rates from Misra et al (10) and Wexner et al (11).

\section{Individual gastroenterologists}

Nine gastroenterologists performed the screening colonoscopies at the OEC. One gastroenterologist examined only 15 patients. He reached the cecum in all 15 cases and $50 \%$ of his patients had polyps. His results were included for completeness, but were not further analysed. Of the remaining eight physicians, three examined more than 800 patients each, one examined over 400 and two examined more than 200 patients. All of these gastroenterologists achieved more than a $98 \%$ completion rate to the cecum. The remaining two gastroenterologists achieved a 93\% and 95\% completion rate, respectively, but they only completed 62 examinations. With this smaller number, their CIs are much larger; thus, there is no statistically significant difference between their completion rate and the overall group rate of $98.98 \%$ (Table 3).

The overall adenoma rate for the entire group was $25.47 \%$. The individual detection rate for each endoscopist varied from $15.83 \%$ to $33.84 \%$. Two gastroenterologists, both with greater than 800 patients examined, found adenomas in a mean of 30.3 and 33.84 patients, respectively. The other six had an adenoma detection rate of between $15.83 \%$ and $20.97 \%$ (Table 3 ).

\section{DISCUSSION}

In Canada, wait times for screening colonoscopies do not meet nationally recommended guidelines. Hospital infrastructure cannot support the current Canadian demand. As a result, out-of-hospital screening colonoscopy has arisen to meet the obvious need. In Ontario, there has been concern about the quality and safety of office-based endoscopy. These concerns include higher rates of incomplete procedures, missed cancer and lack of proof of quality assurance (5). 
TABLE 3

Primary end points and endoscopist comparison

\begin{tabular}{|c|c|c|c|c|c|c|c|c|}
\hline \multirow[b]{2}{*}{ Endoscopist } & \multirow[b]{2}{*}{$\begin{array}{c}\text { Procedures, } \\
\mathbf{n}\end{array}$} & \multirow{2}{*}{$\begin{array}{l}\text { Time to } \\
\text { reach } \\
\text { cecum, min }\end{array}$} & \multicolumn{3}{|c|}{ Withdrawal time } & \multirow{2}{*}{$\begin{array}{c}\text { Cecal } \\
\text { intubation rate, } \\
\%(95 \% \mathrm{Cl})\end{array}$} & \multirow{2}{*}{$\begin{array}{c}\text { Patients } \\
\text { with adenomas, } \\
\%(95 \% \mathrm{Cl})\end{array}$} & \multirow[b]{2}{*}{$\begin{array}{l}\text { Adenomas per } \\
\text { patient (mean) }\end{array}$} \\
\hline & & & Total, min & $\begin{array}{l}\text { When polyps } \\
\text { removed, min }\end{array}$ & $\begin{array}{l}\text { With no polyps } \\
\text { removed, min }\end{array}$ & & & \\
\hline 1 & 981 & 5.07 & 8.06 & 9.05 & 7.26 & 98.78 (98.3-99.1) & $20.59(18.2-23.2)$ & 0.34 \\
\hline 2 & 853 & 6.93 & 9.30 & 10.71 & 6.86 & 99.41 (98.6-99.7) & $30.36(27.4-33.5)$ & 0.57 \\
\hline 3 & 62 & 18.42 & 11.58 & 16.79 & 8.02 & 93.55 (84.5-97.5) & 19.35 (11.5-30.9) & 0.31 \\
\hline 4 & 278 & 7.28 & 7.05 & 9.28 & 5.99 & 99.28 (97.4-99.8) & $15.83(12.0-20.4)$ & 0.23 \\
\hline 5 & 62 & 15.20 & 10.92 & 12.59 & 7.33 & 95.16 (86.7-98.2) & $20.97(12.7-32.7)$ & 0.27 \\
\hline 6 & 416 & NA & NA & NA & NA & 98.56 (96.9-99.3) & $20.91(17.3-25.1)$ & 0.35 \\
\hline 7 & 848 & 7.88 & 13.81 & 15.06 & 11.50 & 99.41 (98.6-99.7) & $33.84(30.7-37.1)$ & 0.70 \\
\hline 8 & 15 & NA & NA & NA & NA & 100.00 & 53.33 & 0.73 \\
\hline 9 & 226 & 8.61 & 6.61 & 9.51 & 5.15 & 99.56 (97.6-99.9) & $18.14(13.7-23.7)$ & 0.25 \\
\hline Total OEC & 3741 & 7.47 & 9.75 & 11.72 & 7.57 & 98.98 (97.6-99.3) & $25.47(24.1-26.9)$ & 0.46 \\
\hline
\end{tabular}

NA Not available; OEC Oakville Endoscopy Centre

TABLE 4

Indication and adenoma/cancer rate

\begin{tabular}{lccc}
\hline & \multicolumn{3}{c}{ Patients } \\
\cline { 2 - 4 } $\begin{array}{c}\text { Patient indication for } \\
\text { screening colonoscopy }\end{array}$ & Adenomas, \% & $\begin{array}{c}\text { Advanced } \\
\text { adenomas, \% }\end{array}$ & Cancer, \% \\
\hline $\begin{array}{c}\text { Average-risk } \\
(n=2596)\end{array}$ & 25.96 & 3.16 & 0.46 \\
$\begin{array}{l}\text { Family history } \\
(n=985)\end{array}$ & 23.45 & 3.65 & 0.30 \\
$\begin{array}{l}\text { Polyp surveillance } \\
(n=107)\end{array}$ & 27.10 & 2.80 & 0.00 \\
$\begin{array}{c}\text { Cancer surveillance } \\
(n=17)\end{array}$ & 17.65 & 5.88 & 0.00 \\
$\begin{array}{l}\text { Positive fecal occult blood } \\
\text { test (n=36) }\end{array}$ & 44.44 & 11.11 & 8.33 \\
$\begin{array}{c}\text { Total Oakville Endoscopy } \\
\text { Centre colonoscopies } \\
(n=3741)\end{array}$ & 25.47 & 3.37 & 0.48 \\
\hline
\end{tabular}

The OEC is unique in that its sole focus is screening and surveillance in asymptomatic patients. By redirecting healthy low-risk screening patients from the hospital system, the OEC has increased access to hospital for symptomatic higher-risk patients. At the OEC, patient safety is maximized by performing asymptomatic screening on preselected patients rather than open-access endoscopy. The current waiting time for screening colonoscopy at the OEC is approximately two months, which is within the accepted CAG guidelines. The mandate of the $\mathrm{OEC}$ is to ensure that the procedures are performed at, or better than, hospital standards, and the CPSO and CCO guidelines. These include quality measures involving staffing, infection control and reprocessing, sedation and single-use accessories. The clinic is also designed to have a more relaxed atmosphere with multiroom audio and video entertainment and a less formal/sterile esthetic design relative to a hospital to minimize patient anxiety. In addition, all endoscopists are trained gastroenterologists who have active hospital privileges, and most have additional endoscopic training beyond core gastroenterology training. Complications and unexpected diseases such as inflammatory bowel disease are followed by the OEC physicians because they all have hospital privileges and can provide local office follow-up.
TABLE 5

Adenoma detection by age group

\begin{tabular}{lccc}
\hline Age group, years & $\begin{array}{c}\text { Patients with } \\
\text { adenomas, } \mathbf{n}\end{array}$ & $\begin{array}{c}\text { Patients per } \\
\text { age group, } \mathbf{n}\end{array}$ & $\begin{array}{c}\text { Adenoma detection } \\
\text { rate per patient age } \\
\text { breakdown, \% }\end{array}$ \\
\hline$<40$ & 5 & 57 & 8.77 \\
$40-50$ & 119 & 626 & 19.01 \\
$51-70$ & 753 & 2836 & 26.55 \\
$>70$ & 76 & 222 & 34.23 \\
Totals for OEC & 953 & 3741 & 25.47 \\
\hline
\end{tabular}

OEC Oakville Endoscopy Centre

To prove quality, a customized Web-based database was created to track known and suspected measures of quality colonoscopy or areas thought to be deficient in previous office-based endoscopy centres. The average sedation dose of $4.27 \mathrm{mg}$ of midazolam and $99.20 \mu \mathrm{g}$ of fentanyl is similar to that routinely used in hospital practice, and ensures patient comfort and safety $(17,18)$. The unit has the full capacity of a level II endoscopy centre as described by the CCO Colonoscopy Standards document (8).

Careful examination of the entire colon is clearly paramount to maximizing the yield of screening colonoscopy in cancer prevention. The routine practice at the $\mathrm{OEC}$ is to intubate the terminal ileum to confirm cecal intubation, and photo documentation of the ileum and cecal pole results in a reproducible and formal proof of a complete examination. The 98.98\% cecal intubation rates achieved at the OEC are at least comparable with previous studies of in-hospital and academic institution procedures (8).

Because the OEC is a new institution, comment on the potential for missed adenomas (and cancer) cannot be made at this time. However, the best reassurance in this circumstance would be the better than average adenoma detection rate of $25.47 \%$ of all patients and polyp detection rate of $46.11 \%$ in a population with an average patient age of 57.1 years $(8,13,20)$. Similar to previous publications, the present study confirmed an increasing adenoma detection rate with advancing age (Table 5).

Although the sample size for advanced adenoma detection rates in 126 patients $(3.37 \%)$ and cancer in 18 patients $(0.48 \%)$ are small (Table 4$)$, they again are in keeping with published data of similar sized series $(12,13)$. 
As expected, a stool positive for fecal occult blood was a clear predictor of both advanced adenoma and cancer (Table 4). Only a small number of patients in this category (36 patients, or $0.96 \%$ ) were examined at the OEC. This may reflect the fact that the fecal occult blood screening program has only recently started in Ontario, and/or the special resources provided by $\mathrm{CCO}$ for screening this category of patients in hospital settings. The majority of cancers (14 of 18) identified at the OEC were stage 0 or stage 1 . The expectation of cure was therefore high in our asymptomatic patient group in keeping with the benefit of early detection.

Equally important are complication rates. All patients seen at the $\mathrm{OEC}$ are referred via a general practitioner and the vast majority of patients come from a core of the local general practitioners. OEC endoscopists provide the inpatient and $24 \mathrm{~h}$ on-call for the gastroenterology service at all three regional hospitals in our catchment area. Therefore, it would be unusual for a patient not to routinely encounter an OEC physician for inpatient care who had a complication. All patients are given written instructions to contact the OEC at any time, $24 \mathrm{~h}$ a day, with any concerns or possible complications and are given a contact telephone number on their postprocedure information instructions. The referring physicians have also been asked to contact the OEC in the event of a complication and have been given written instructions to do so. In previous studies focusing on complications, health management oraganization-based databases of admission to hospital were used to track complications $(21,22)$. No such database is available at the OEC or within an Ontario database that we are aware of or would have access to.

The capture of complications is still a potential weakness in our paper; however, this was the most practical and accurate solution for reporting complications available to us.

The rates, for both perforation (one in 3741 examinations [0.027\%]), and bleeding (two in 3741 examinations [0.053\%]) at a minimum, match published data sets (Table 1 ).

Among the individual gastroenterologists, the completion rate is close to the theoretical maximum. The failure rate to the cecum is approximately $1 \%$. There is a numerical trend with two physicians (with smaller patient numbers) having slightly lower completion rates than the other six, but these are still at an acceptable 93\% and 95\% completion rate, respectively. While the cecal intubation rate warrants monitoring, we believe that we have other areas to pursue for quality improvement.

A correlation between increasing withdrawal time and increased adenoma detection was observed as per previous studies (Table 3). When comparing physicians in practice with less than or more than five years, a difference was noted in withdrawal time ( $8.41 \mathrm{~min}$ versus $6.16 \mathrm{~min}$ ) and adenoma detection rate $(27.84 \%$ versus $18.84 \%)$ (Table 3$)$. The increased adenoma detection rate in less-experienced doctors has been previously described (19). Debate as to significance of the additional adenomas detected with less-experienced physicians exists.

As reported by Chen and Rex (20) and others (9), there is a twofold difference in the rate of adenoma detection between $\mathrm{OEC}$ endoscopists at the high and low ends of the range. These CIs do not overlap and they are therefore statistically significant $(15.83 \pm 4.4 \%$ versus $33.84 \pm 3.2 \%)$. We have attempted to further examine these performance differences by experience and withdrawal time. The average withdrawal time of $7.57 \mathrm{~min}$ when no polyps were removed for all physicians at the OEC exceeds published recommendations for polyp detection $(9,19)$. However, our data would suggest that withdrawal time is the most promising area for intervention to change the variation in the detection rate. Two of the three endoscopists with the longest withdrawal times had the highest adenoma detection rates. The two with the shortest withdrawal times detected the fewest adenomas. However, this may not be the whole story. The endoscopist with the second longest withdrawal time had a low polyp detection rate (Table 3 ). We intend to present these data in detail to the OEC endoscopists and introduce more careful timing of withdrawal in our next series. This will include alarms at intervals for each segment of the colon and studying only screening patients who were not previously examined.

This is the first Canadian study investigating quality measures in an office-based endoscopy clinic. The OEC data demonstrate that office-based screening colonoscopies, performed by well-trained physicians using adequate sedation and hospitalgrade equipment and staff, result in outcomes at least equal to, or better than, those of published academic and community hospital practices. Office-based endoscopy programs should publicly report factors known to influence outcomes for quality assurance. These include use of sedation, cecal intubation rates, withdrawal times, adenoma and cancer detection rates, the training of endoscopists and complication rates.

\section{SUMMARY}

The present study has shown that office-based colonoscopy can be performed with the same quality as in-hospital procedures. Given the increased demands for screening colonoscopies and the hospital resource constraints, office-based colonoscopies for 'average-risk' patients are therefore a viable option for the future of screening colonoscopy in Canada, assuming appropriate documentation of quality measures are in place.

ACKNOWLEDGEMENTS: The authors wish to thank all OEC physicians including Dr Barry Lumb, Dr David Morgan, Dr John Marshall, Dr Robert Spaziani and Dr Mark Jones. A special thank you to Natasha Killy, the OEC office manager, for her patience and hard work. Thank you also to Dr Jill Tinmouth for her direction. We would also like to thank all of the OEC staff for their dedication and commitment, especially Dr Shelley Bair.

\section{REFERENCES}

1. Vinden C, Schultz S, Rabeneck L. Use of large bowel procedures in Ontario. ICES Research Atlas 2004; February.

2. Moayyedi P, Tepper J, Hisden R, Rabeneck L. International comparisons of manpower in gastroenterology. Am J Gastroenterol 2007;102:478-81.

3. Leddin D, Armstrong D, Barkun AN, et al. Access to specialist gastroenterology care in Canada: Comparison of wait times and consensus targets. Can J Gastroenterol 2008;22:161-7.

4. Bressler B, Paszat LF, Chen Z, et al. Rates of new or missed colorectal cancers after colonoscopy and their risk factors: A population-based analysis. Gastroenterology 2007;132:96-102.

5. Shah HA, Paszat LF, Saskin R, Stukel TA, Rabeneck L. Factors associated with incomplete colonoscopy: A population-based study. Gastroenterology 2007;132:96-102, 2297-303.

6. Rathgaber SW, Wick TM. Colonoscopy completion and complication rates in a community gastroenterology practice. Gastrointest Endosc 2006;64:556-62.

7. Leddin D, Hunt R, Champion M, et al. Canadian Association of Gastroenterology and the Canadian Digestive Health Foundation: Guidelines on colon cancer screening. Can J Gastroenterol 2004;18:93-9. 
8. Rabenek L, Rumble RB, Axler J, et al. for Cancer Care Ontario's Colonoscopy Standards Expert Panel. Cancer Care Ontario colonoscopy standards: Standards and evidentiary base. Can J Gastroenterol 2007;21(Suppl D):5D-24D.

9. Barclay RL, Vicari JJ, Doughty AS, et al. Colonoscopic withdrawal times and adenoma detection during screening colonoscopy. N Engl J Med 2006;355:2533-41.

10. Misra T, Lalor E, Fedorak RN. Endoscopic perforation rates at a Canadian university teaching hospital. Can J Gastroenterol 2004;18:221-6.

11. Wexner SD, Garbus JE, Singh JJ. Reevaluation of credentialing guidelines. Surg Endosc 2001;15:251-61.

12. Lieberman DA, Weiss DG, Bond JH, et al. Use of colonoscopy to screen asymptomatic adults for colorectal cancer. N Eng J Med 2000;343:162-9.

13. Imperiale TF, Wagner DR, Lin CY, et al. Risk of advanced proximal neoplasms in asymptomatic adults according to the distal colorectal findings. N Eng J Med 2000;343:169-74.

14. Mercer D, Abourbih J, Bradley J, et al. Guidelines for clinical practice parameters and facility standards. Toronto: The College of Physicians and Surgeons of Ontario. 2005. <www.cpso.on.ca/ Publications/endoscopybook.pdf.> (Version current at November 1, 2007).

15. Joint Advisory Group on Gastrointestinal Endoscopy (JAG). Guidelines for the training, appraisal and assessment of trainees in gastrointestinal endoscopy. London: JAG Secretariat, 2004.<www.
acpgbi.org.uk/documents/JAG_2004.pdf.> (Version current at November 1, 2007).

16. Rex DK, Bond JH, Winawer S, et al. Quality in the technical performance of colonoscopy and the continuous quality improvement process for colonoscopy: Recommendations of the U.S. Multi-Society Task Force on Colorectal Cancer. Am J Gastroenterol 2002;97:1296-308.

17. Radaelli F, Meucci G, Terruzzi V, et al. Single bolus of midazolam versus bolus midazolam plus meperidine for colonoscopy: A prospective, randomized, double-blind trial. Gastrointest Endosc 2003;57:329-35.

18. Rodney W, McMillan W, Dabov G, Orientale E, Reeves WP. Sedation associated with a more complete colonoscopy. J Fam Pract 1993;36:394-400.

19. Simmons DT, Harewood GC, Baron TH, et al. Impact of endoscopist withdrawal speed on polyp yield: Implications for optimal colonoscopy withdrawal time. Aliment Pharmacol Ther 2007;24:965-71.

20. Chen SC, Rex DK. Endoscopist can be more powerful than age and male gender in predicting adenoma detection at colonoscopy. Am J Gastroenterol 2007;102:856-61.

21. Gatto NM, Frucht H, Sundararajan V, et al. Risk of perforation after colonoscopy and sigmoidoscopy: A population-based study. J Natl Cancer Inst 2003;95:230-7.

22. Levin TR, Zhao W, Conell C, et al. Complications of colonoscopy in an integrated health care delivery system. Ann Int Med 2006;145:880-6. 


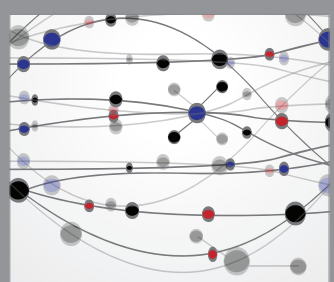

The Scientific World Journal
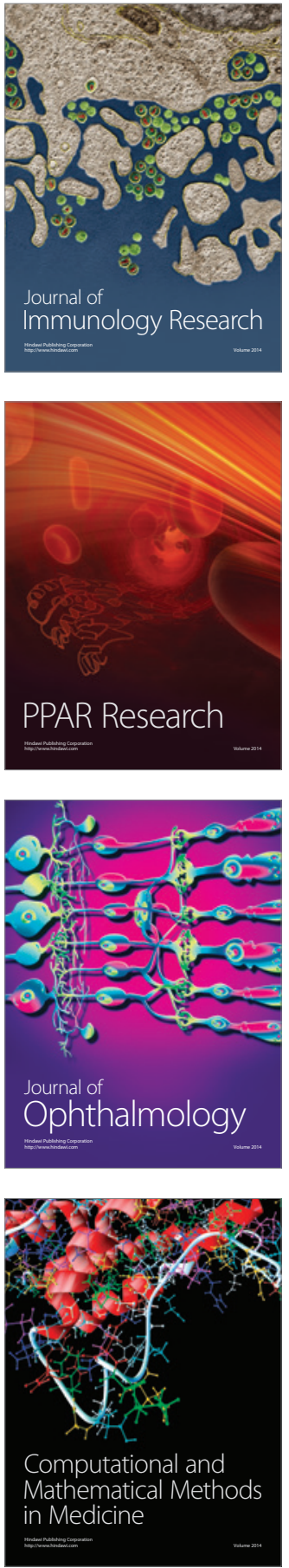

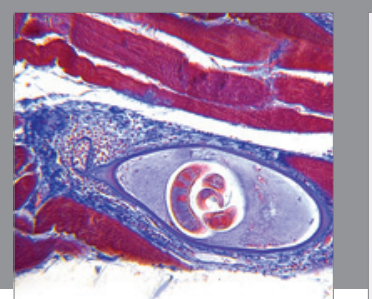

Gastroenterology Research and Practice

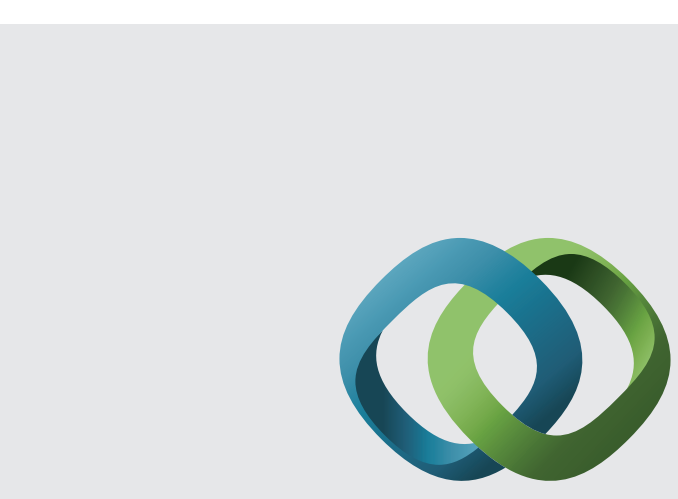

\section{Hindawi}

Submit your manuscripts at

http://www.hindawi.com
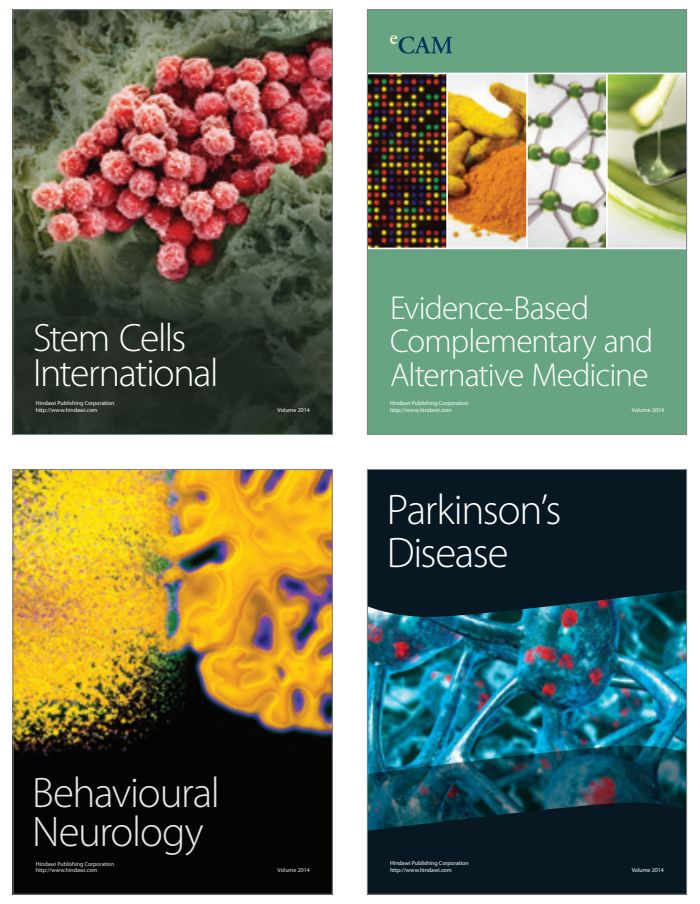
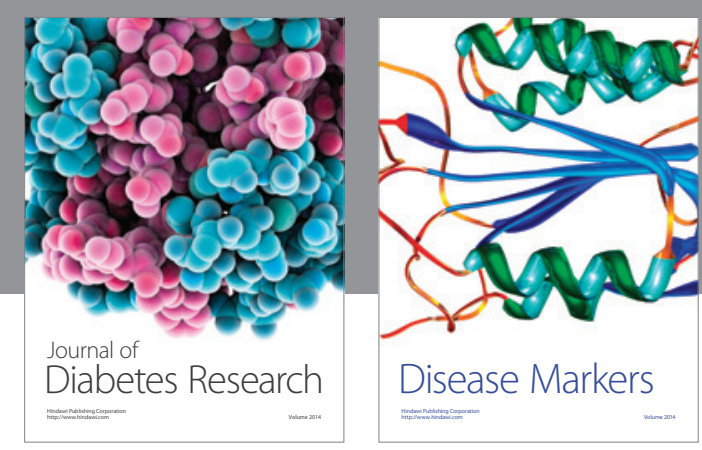

Disease Markers
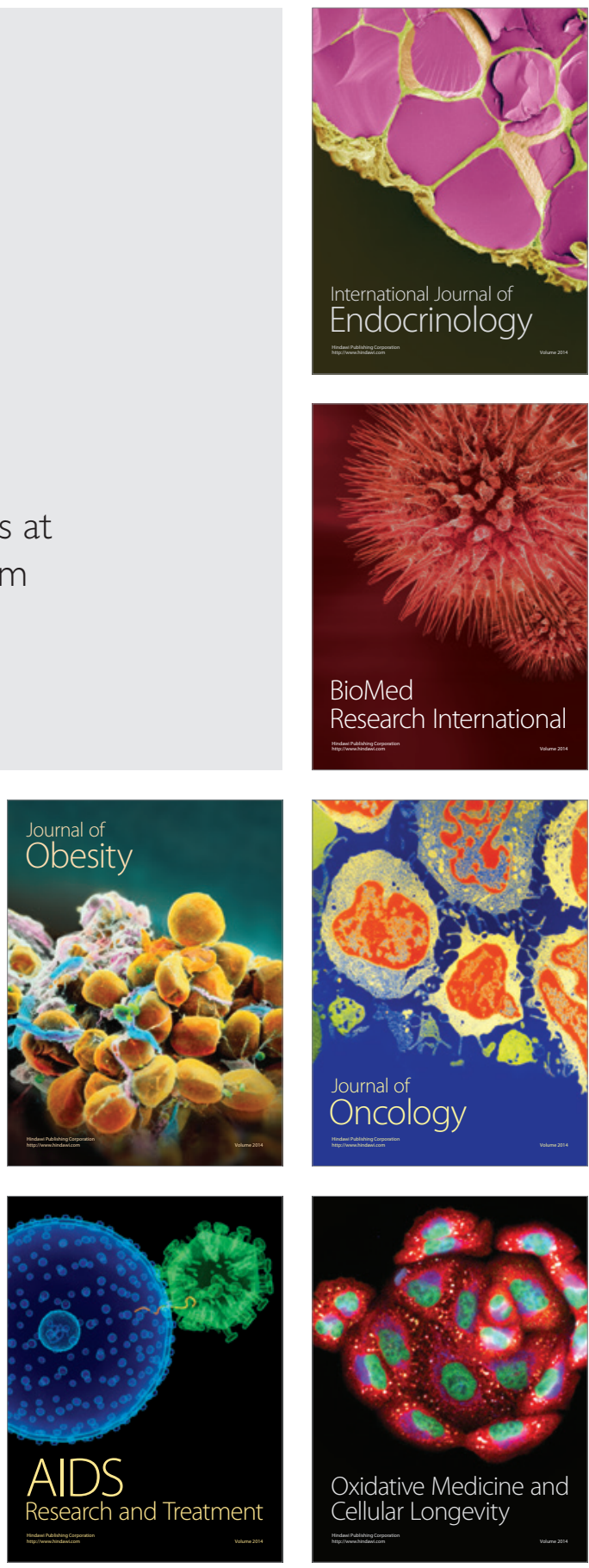